\title{
EFEITO DA COMPACTAČ̃̃ DO SOLO SOBRE A EMERGÊNCIA DE PLÂNTULAS DE SOJA EM SISTEMA PLANTIO DIRETO
}

\author{
Effect of the compacting of the soil on the seed in the emergency of the soy in \\ direct planting system
}

\author{
Alcir José Modolo ${ }^{1}$, Haroldo Carlos Fernandes², Carlos Ernesto Gonçalves Schaefer ${ }^{3}$, \\ João Cleber Modernel da Silveira ${ }^{4}$
}

\begin{abstract}
RESUMO
Objetivou-se no presente trabalho, estudar os efeitos da combinação entre teores de água do solo e cargas aplicadas pela roda compactadora da semeadora-adubadora sobre a emergência de plântulas de soja, em sistema plantio direto. A resistência mecânica do solo à penetração foi determinada quinze dias após a semeadura. $\mathrm{O}$ índice de velocidade de emergência foi determinado pela contagem das plântulas, sendo realizada diariamente até que o número de plântulas emergidas se apresentasse constante por três dias consecutivos. $\mathrm{O}$ maior índice de velocidade de emergência (IVE) ocorreu no teor de água igual a $0,33 \mathrm{~kg} \mathrm{~kg}^{-1}$ e na carga de $86,21 \mathrm{~N}$. A carga máxima de $140 \mathrm{~N}$, aplicada pela roda compactadora sobre a semente, causou encrostamento superficial do solo, retardando a emergência das plântulas.
\end{abstract}

Termos para indexação: Mecanização agrícola, semeadura, Glycine max.

\section{ABSTRACT}

The present work aimed to study the effects of the combination between the soil water contents and the loads applied by the press wheel of fertilizer on soybean seed emergency of in no-tillage system. The mechanical resistance of the soil to the penetration was determined fifteen days after the sowing. The index of emergency speed was determined by seedlings counting, which was carried out daily until the numbers seedling were maintenance constant for three consecutive days. The best seedling emergence speed index occurred whit soil water contents of $0,33 \mathrm{~kg} \mathrm{~kg}^{-1}$ and loads of $86,21 \mathrm{~N}$. The maximum load of $140 \mathrm{~N}$ applied by the press wheel on the seed caused a superficial crust of the soil, delaying seedlings emergence.

Index terms: Agricultural mechanization; sowing; Glycine max.

\section{(Recebido em 24 de outubro de 2006 e aprovado em 12 de fevereiro de 2007)}

\section{INTRODUÇÃO}

A agricultura vem passando por transformações tecnológicas significativas em função da necessidade de conciliar o manejo conservacionista do solo com a busca constante da redução dos custos de produção. Dessa forma, o sistema plantio direto passou a ser utilizado com grande intensidade no Brasil.

De acordo com Lange (2002), o sistema de plantio direto é um componente indispensável à agricultura sustentável. Um método de manejo do solo que conserve a estrutura do solo e mantenha os restos culturais sobre a superfície, no período que vai da colheita até ao próximo plantio, é indicado como a melhor forma de se conservar a umidade e evitar a erosão (CARDOSO, 1993).
Para a cultura da soja, assim como nas demais culturas anuais, as operações de semeadura e adubação revestem-se de grande importância, pois eventuais problemas somente serão detectados após a germinação das sementes e o seu desenvolvimento, quando a correção além de difícil e onerosa, compromete a produtividade.

A disponibilidade de água no solo é considerada uma das causas mais comuns da baixa germinação de sementes de soja, uma vez que períodos de estiagem são freqüentes na época de semeadura, porém a emergência e o desenvolvimento das plântulas está, também, na dependência de seu potencial fisiológico (MORAES \& MENEZES, 2003). Hauser (1986), afirma que muitos fatores afetam a germinação e o estabelecimento das plântulas, incluindo a idade da semente, a porcentagem de

\footnotetext{
'Doutor em Mecanização Agrícola - Curso de Agronomia/COAGR - Universidade Tecnológica Federal do Paraná/UTFPR - Via do Conhecimento, Km 01 Campus de Pato Branco - Cx. P. 571 - 85501-970 - Pato Branco, PR - alcir@utfpr.edu.br

2Doutor em Mecanização Agrícola - Departamento de Engenharia Agrícola/DEA - Universidade Federal de Viçosa/UFV - Avenida Peter Henry Rolfs, s/n - Campus Universitário - 36570-000 - Viçosa, MG - haroldo@ufv.br

${ }^{3}$ Doutor em Solos - Departamento de Solos/DPS - Universidade Federal de Viçosa/UFV - Avenida Peter Henry Rolfs, s/n - Campus Universitário 36570-000 - Viçosa, MG - carlos.schaeffer@ufv.br

${ }^{4}$ Doutorando em Solos - Departamento de Engenharia Agrícola/DEA - Universidade Federal de Viçosa/UFV - Avenida Peter Henry Rolfs, s/n - Campus Universitário - 36570-000 - Viçosa, MG - jcmodernel@uol.com.br
} 
germinação e o vigor das plântulas. Da mesma forma Hillel (1972), citado por Silva (1990), relaciona fatores como a crosta na superfície do solo, salinidade e suprimento de oxigênio. Dentre os fatores físicos do solo Hauser (1986), afirma que o conteúdo de água do solo é o maior controlador da germinação e crescimento das plântulas, seguido da temperatura e do grau de contato entre a semente e a água líquida dos capilares do solo.

Silva (2002) relata que, no processo de semeadura de culturas anuais, o condicionamento físico do solo ao redor das sementes reveste-se de importância capital para o bom desenvolvimento inicial da cultura, assegurando uma população adequada de plantas. Dentre os fatores que condicionam o meio ambiente do solo, a umidade, a temperatura e a aeração são primordiais para a germinação (NABI et al., 2000). Porém, para que essa semente já germinada dê continuidade ao crescimento da plântula, deve-se incluir a esses fatores, a resistência mecânica do solo à penetração. Importante se faz citar, que esses fatores são diretamente influenciados pelo estado de compactação do solo ao redor da semente.

Uma boa cobertura e uma boa compactação do solo sobre a semente irão depender entre outros fatores, dos mecanismos de cobertura e compactação, do teor de água do solo e da profundidade de colocação de sementes (SILVA, 2002).

Silva et al. (1991) verificaram a influência de quatro diferentes modelos de rodas compactadoras sobre o condicionamento físico do solo, utilizando-se três níveis de compactação, e afirmaram que as mesmas alteram o comportamento hídrico do solo na região de semeadura, além de elevar a densidade e a resistência à penetração no plano vertical da linha de semeadura. A velocidade de emergência e emergência total das plantas de feijoeiro foram afetadas pelas pressões de compactação. À medida que a compactação aumentou, as plântulas tiveram sua emergência retardada e diminuída para todas as rodas testadas. O mesmo não foi encontrado por Furlani et al. (2001) quando trabalharam com a cultura do milho em quatro níveis de compactação e três profundidades de semeadura.

Objetivou-se aqui, estudar os efeitos da combinação entre três teores de água do solo e quatro cargas aplicadas pela roda compactadora da semeadora-adubadora sobre a resistência mecânica do solo à penetração na linha de semeadura, e a velocidade de emergência da cultura da soja, em sistema plantio direto.

\section{MATERIAL E MÉTODOS}

A pesquisa foi desenvolvida na Cooperativa Central Agropecuária de Desenvolvimento Tecnológico e
Econômico Ltda - COODETEC, localizado lateralmente à BR 467, Km 98, sentido Cascavel - Toledo, no estado do Paraná, em um Latossolo Vermelho Distroférico típico. Utilizou-se o esquema de parcelas subdivididas, em que as parcelas constituíram os três teores de água (U1, U2 e U3), correspondentes a 0,$27 ; 0,31$ e $0,36 \mathrm{~kg} \mathrm{~kg}^{-1}$, respectivamente, e as subparcelas os quatro níveis de carga aplicada pela roda compactadora (C1, C2, C3 e C4), correspondentes a $0,50,90$ e $140 \mathrm{~N}$, respectivamente, no delineamento em blocos ao acaso, com quatro repetições.

Utilizou-se a cultivar de soja super precoce CD 216, com $87 \%$ de germinação mínima e $98 \%$ de pureza. Utilizouse adubo de formulação 0-20-20 (N-P-K), sendo aplicado $300 \mathrm{~kg} \mathrm{ha}^{-1}$ por ocasião da semeadura.

Para a semeadura da soja, utilizou-se como fonte de tração um trator agrícola com potência de 75,8 kW (103 cv) e uma semeadora-adubadora de precisão de arrasto, com mecanismos sulcadores do tipo haste para fertilizantes e discos duplos defasados para sementes e roda compactadora de borracha, tipo convexa com $330 \mathrm{~mm}$ (13") de diâmetro e $170 \mathrm{~mm}$ de largura. A semeadora foi regulada visando profundidade de plantio de $5 \mathrm{~cm}$.

Para determinar o nível de carga aplicada pela roda compactadora sobre a semente utilizou-se uma célula de carga com capacidade de $19,6 \mathrm{kN}$, acoplada sobre a roda compactadora. O pino que fixa a roda compactadora foi retirado de modo que ela ficasse livre e toda a carga fosse aplicada diretamente na célula de carga. As cargas aplicadas pela roda compactadora sobre a semente foram visualizadas por um equipamento para esse fim (Figura 1).

Os quatro níveis de cargas aplicadas pela roda compactadora sobre a semente foram $\mathrm{C} 1=0 \mathrm{~N}, \mathrm{C} 2=50 \mathrm{~N}$, C3 $=90 \mathrm{~N}$ e C4 $=140 \mathrm{~N}$, obtidos de acordo com as opções de regulagem da semeadora-adubadora. Para a obtenção da carga $\mathrm{C} 1$, a roda compactadora foi fixada em uma posição em que não exercia pressão sobre o solo.

Os níveis desejados do teor de água do solo, para a condução dos ensaios de campo, foram obtidos após uma precipitação pluviométrica. Após a ocorrência da precipitação realizaram-se os ensaios com os tratamentos compostos pelo maior teor de água (U3). Na seqüência, quando o solo encontrava-se nos teores de água desejados, realizaram-se os ensaios com os tratamentos compostos pelos teores de água U2 e U1, respectivamente.

A caracterização física do solo antes do plantio foi feita determinando-se a densidade do solo, a densidade de partículas, a porosidade total, conforme (EMBRAPA, 1997) e a resistência mecânica do solo à penetração, por meio de um penetrômetro eletrônico desenvolvido por Tieppo (2004). 
Após a semeadura foram avaliadas a resistência mecânica à penetração na linha e o índice de velocidade de emergência das plântulas de soja. Quinze dias depois da passagem da semeadora-adubadora, com o uso do penetrômetro eletrônico descrito acima, foi determinada a resistência mecânica do solo à penetração sobre a linha de semeadura, tendo sido realizadas dez medições por unidade experimental, obtendo-se os valores na faixa de 0 a $20 \mathrm{~cm}$ de profundidade.

O índice de velocidade de emergência de plântulas foi avaliado em um comprimento de 10 metros na linha central de semeadura, segundo a metodologia proposta por Maguire (1962).

Os resultados obtidos para a caracterização física do solo antes da instalação do experimento foram submetidos à análise de variância, e as médias foram comparadas pelo teste de Tukey, a 5\% de probabilidade. Para a resistência mecânica do solo à penetração, os resultados foram apresentados na forma de gráficos, e os dados referentes ao índice de velocidade de emergência foram submetidos à análise em superfície de resposta por meio do procedimento GLM do "Statistical Analysis System" (SAS). O modelo foi escolhido com base no teste para a falta de ajustamento do modelo de superfície, na significância do teste $\mathrm{t}$ dos coeficientes de regressão, a 5\% de probabilidade.

\section{RESULTADOS E DISCUSSÃO}

\section{Caracterização física do solo antes do plantio}

Os resultados obtidos através da análise de variância permitem concluir que, as unidades experimentais que foram alocadas para receber os 12 tratamentos estavam sob condições bastante homogêneas, com relação à densidade do solo, densidade de partículas e porosidade total do solo, apresentando valores médios de $1,21 \mathrm{~kg} \mathrm{dm}^{-}$ ${ }^{3}, 2,84 \mathrm{~kg} \mathrm{dm}^{-3} \mathrm{e} 0,58 \%$, respectivamente.

A resistência mecânica do solo à penetração integra os efeitos da densidade e da umidade nas condições físicas do solo necessárias para o crescimento das raízes. Com a finalidade de obter melhor visualização e interpretação dos dados, os gráficos de resistência mecânica do solo à penetração foram divididos em função dos três teores de água no solo.

Os valores médios absolutos da resistência mecânica do solo à penetração realizado antes do plantio, observam-se na Figura 2.

A resistência à penetração apresentou tendência de aumento até a profundidade de $8,0 \mathrm{~cm}$, indicando a presença de uma camada de solo mais compactada, devido ao intenso tráfego de máquinas e implementos agrícolas, na superfície do solo. No entanto, os tratamentos U2C2 e U1C1 tenderam a apresentar a menor resistência mecânica do solo à penetração na profundidade de $8,0 \mathrm{~cm}$, com valores de 2,02 e 2,03 $\mathrm{MPa}$, respectivamente. Por outro lado, os tratamentos U1C3 e U3C4 tenderam a apresentar as maiores resistências, cujos valores observados foram 2,44 e 2,43 $\mathrm{MPa}$, respectivamente.

Observou-se também que, na camada entre 8,0 e 20,0 cm a resistência à penetração tendeu a diminuir com o aumento da profundidade, e que apenas nas parcelas experimentais, onde se utilizou o tratamento U3C4, o solo não apresentou resistência à penetração semelhante às demais (Figura 2c). O teor de água do solo no momento da medida da resistência mecânica do solo à penetração na camada de $0-15 \mathrm{~cm}^{\text {foi }} 0,30 \mathrm{~kg} \mathrm{~kg}^{-1}$.
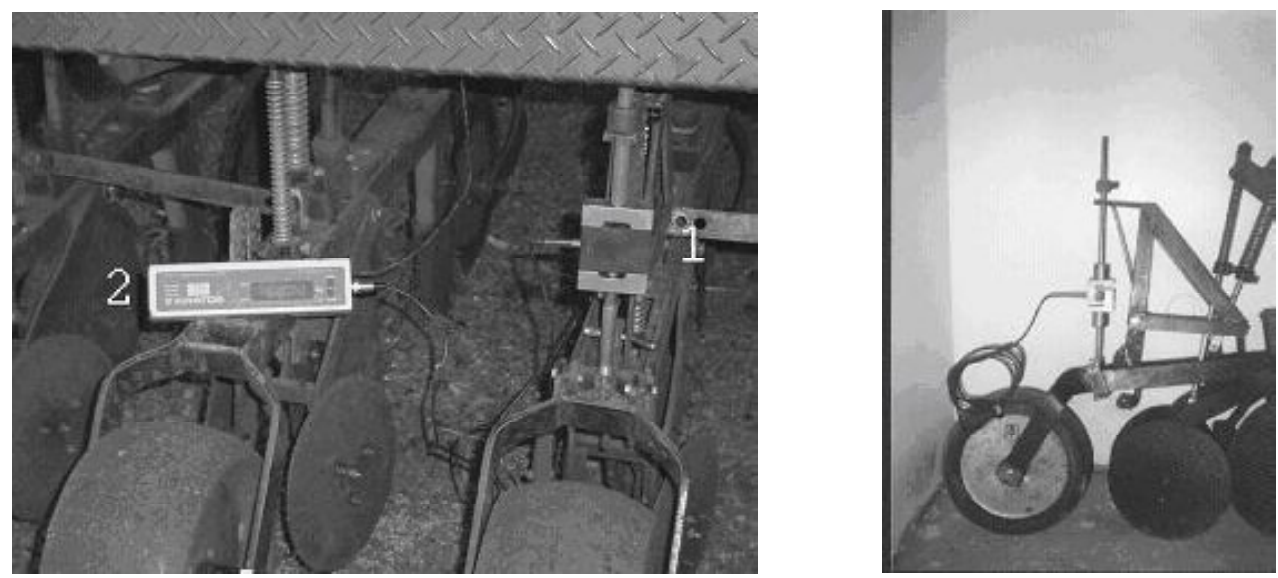

Figura 1 - Vista geral dos equipamentos utilizados na determinação das cargas aplicadas no solo pela roda compactadora: (1) célula de carga, (2) visor. 


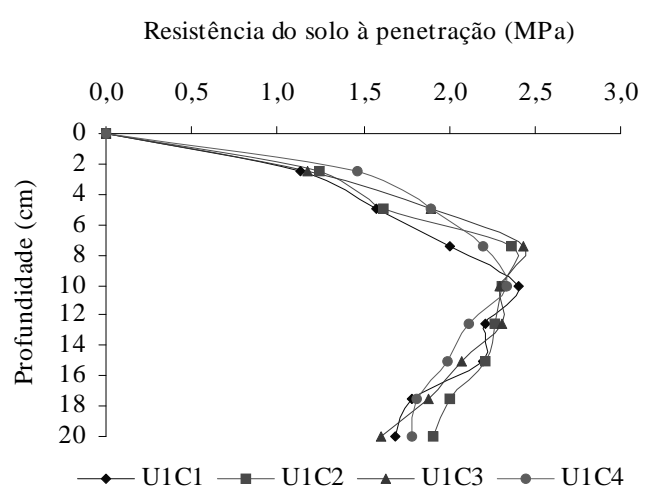

(a)

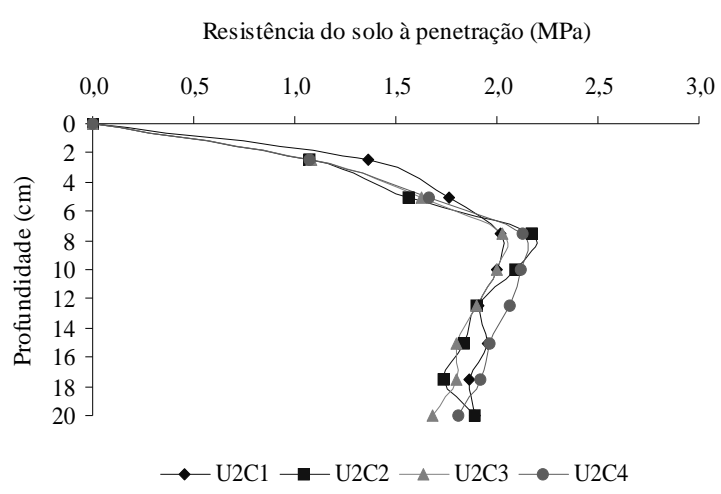

(b)

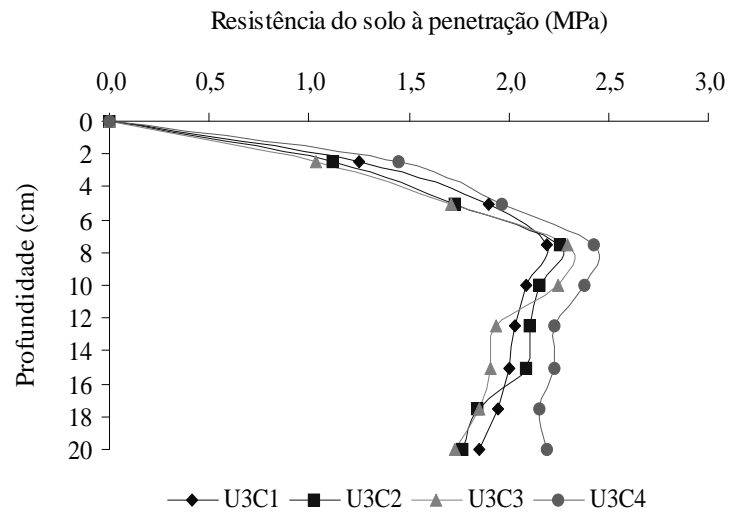

(c)

Figura 2 - Resistência mecânica do solo à penetração (MPa) para o teores de água: a) $\mathrm{U} 1=0,27 \mathrm{~kg} \mathrm{~kg}^{-1}$; (b) $\mathrm{U} 2=0,31 \mathrm{~kg}$ $\mathrm{kg}^{-1}$ e c) $\mathrm{U} 3=0,36 \mathrm{~kg} \mathrm{~kg}^{-1}$, na profundidade de $0-20 \mathrm{~cm}$.

\section{Resultados Pós-plantio}

Os valores médios absolutos da resistência mecânica do solo à penetração no sulco de semeadura, em função dos teores de água do solo constata-se na Figura 3.

Na camada entre 0 e $6,0 \mathrm{~cm}$ de profundidade, o solo apresentou resistência mecânica à penetração semelhante para todos os tratamentos estudados. Observou-se ainda que, na profundidade de $6,0 \mathrm{~cm}$ (profundidade de semeadura), o tratamento $\mathrm{U} 3 \mathrm{C} 1$ tendeu a apresentar menor resistência à penetração, com valor de $1,08 \mathrm{MPa}$, enquanto que o tratamento $\mathrm{U} 3 \mathrm{C} 4$ tendeu a apresentar maior resistência à penetração, com valor de 1,86 MPa. Isso se explica pelo fato dos tratamentos $\mathrm{U} 3 \mathrm{C} 1$ e U3C4 serem compostos pelo maior teor água no solo $\left(0,36 \mathrm{~kg} \mathrm{~kg}^{-1}\right) \mathrm{e}$ pelas cargas $(0$ e $140 \mathrm{~N})$, respectivamente. Nenhum dos valores encontrados até $6,0 \mathrm{~cm}$ de profundidade superou os valores considerados críticos por (TORMENA et al., 1998) que é de (2,0 MPa). Verificou-se também que, na profundidade do sulco (em torno de $10,0 \mathrm{~cm}$ ), os tratamentos compostos pelos teores de água U1 e U3 apresentaram valores de resistência à penetração semelhantes.

O teor de água do solo no momento da determinação da resistência mecânica do solo à penetração, no sulco de semeadura na camada de $0-15 \mathrm{~cm}$ foi $0,32 \mathrm{~kg} \mathrm{~kg}^{-1}$.

Independente dos tratamentos utilizados constatou-se que a partir da profundidade de $10,0 \mathrm{~cm}$, os valores de resistência do solo à penetração aumentaram até atingirem valores críticos (2,0 MPa). Esse aumento da resistência acarreta a redução da porosidade, da continuidade de poros, da permeabilidade e da disponibilidade de nutrientes e água. Esse processo afeta o crescimento e o desenvolvimento radicular, aumenta a densidade do solo, o consumo de combustível das máquinas no preparo dos solos compactados e aumenta a erosão do solo, pela menor infiltração de água. 


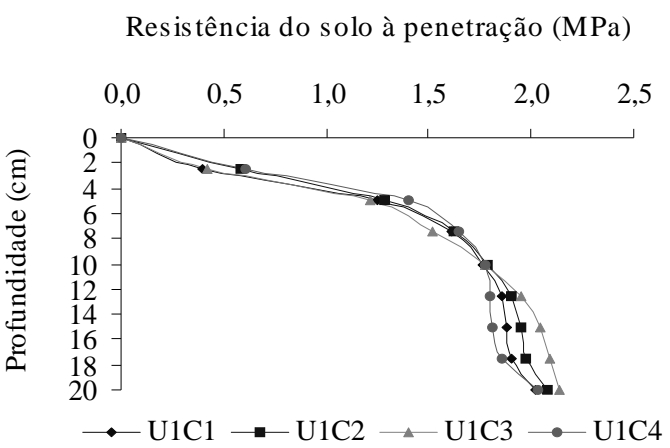

(a)
Resistência do solo à penetração (MPa)

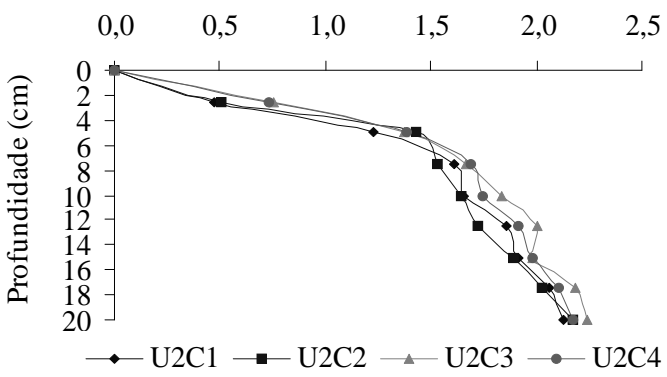

(b)

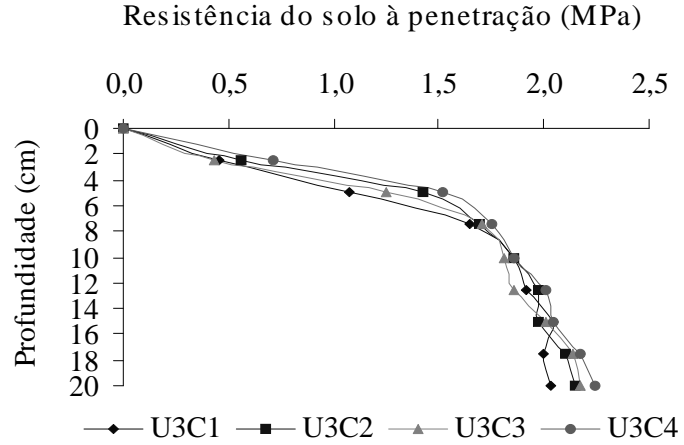

(c)

Figura 3 - Resistência mecânica do solo à penetração (MPa) para o teores de água: a) $\mathrm{U} 1=0,27 \mathrm{~kg} \mathrm{~kg}^{-1} ;(\mathrm{b}) \mathrm{U} 2=0,31 \mathrm{~kg}$ $\mathrm{kg}^{-1}$ e c) $\mathrm{U} 3=0,36 \mathrm{~kg} \mathrm{~kg}^{-1}$, na profundidade de $0-20 \mathrm{~cm}$.

\section{Índice de velocidade de emergência das plântulas}

O modelo de superfície de resposta estimado usando as médias dos tratamentos para a variável IVE observa-se na Equação 3.

$$
\begin{gathered}
\hat{I V E}=-180,28+1285,34 U-1998,61 U^{2}+0,129275 C-0,39135 U C \\
\mathrm{R}^{2}=0,79
\end{gathered}
$$

A equação acima prevê os níveis ótimos de carga aplicada pela roda compactadora sobre a semente (C) e teores de água do solo (U), representada pelas seguintes condições: $\mathrm{C}=86,21 \mathrm{Ne} \mathrm{U}=0,33 \mathrm{~kg} \mathrm{~kg}^{-1}$, que proporcionam um índice de velocidade de emergência (IVE) máximo de 26,24 .

A superfície de resposta tridimensional ajustada para os dados de índice de velocidade de emergência (IVE) verifica-se na Figura 4, em que, os menores IVE foram encontrados nas áreas correspondentes às cargas entre $0 \mathrm{e}$ $50 \mathrm{~N}$ e entre 90 e $140 \mathrm{~N}$. Isso se explica pela ocorrência de bolsas de ar sobre a semente, nos tratamentos compostos pelas cargas 0 e $50 \mathrm{~N}$, ocasionando um contato inadequado entre o solo e a semente, dificultando a absorção de água, retardando assim o processo de germinação e emergência das plântulas. Entretanto, os menores índices de emergência observados, principalmente nos tratamentos compostos pela carga de $140 \mathrm{~N}$ ocorreram pelo encrostamento superficial

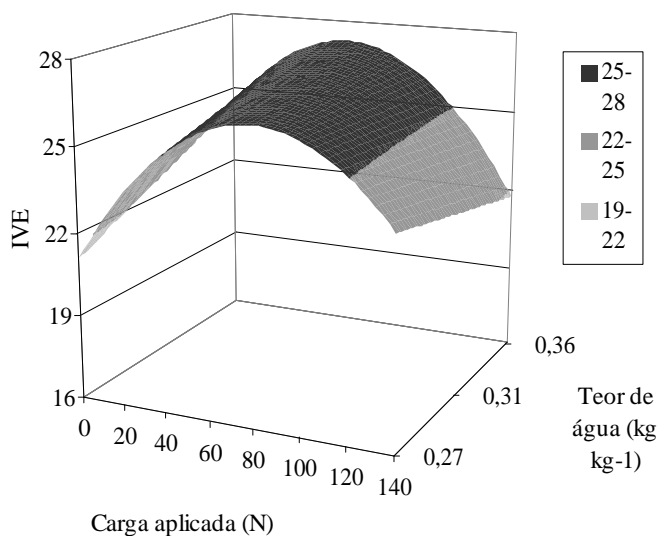

Figura 4 - Efeito das cargas aplicadas pela roda compactadora (C) e dos teores de água do solo (U) sobre o índice de velocidade de emergência (IVE). 
ocorrido nesses tratamentos, dificultando a penetração de oxigênio, fazendo com que a planta tenha que consumir mais energia para emergir. Prado et al. (2001) ao avaliarem os efeitos da compressão do solo e profundidade de semeadura no índice de velocidade de emergência (IVE) de plântulas de milho, observaram que a baixa compressão do solo, ao redor da semente, reduziu o IVE. Os autores atribuíram esse fato à reduzida taxa de transmissão de água e nutrientes pela interface solo-semente-raiz.

\section{Marcha de emergência}

A marcha de emergência das plântulas de soja em função do teor de água do solo e das cargas aplicadas pela roda compactadora sobre a semente apresentam-se nas Figuras 5a e 5b, respectivamente.

Verifica-se na Figura 5, que houve um incremento no número de plantas emergidas, no período compreendido entre o sexto e o décimo dia após o plantio. Constatou-se também que $33,7 \%$ das sementes semeadas no teor de água de $0,27 \mathrm{~kg} \mathrm{~kg}^{-1}$ emergiram aos sete dias após a semeadura, enquanto, na mesma data, somente

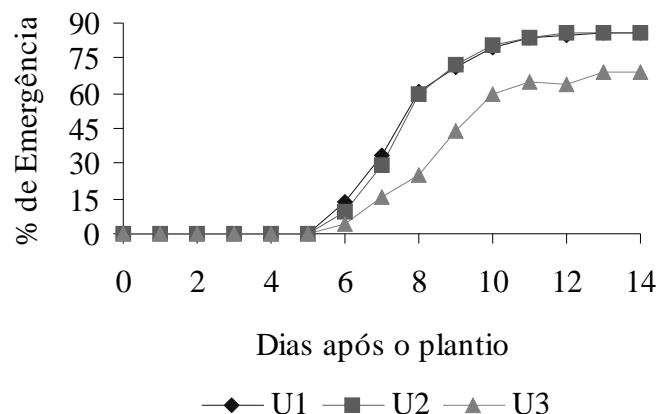

(a)

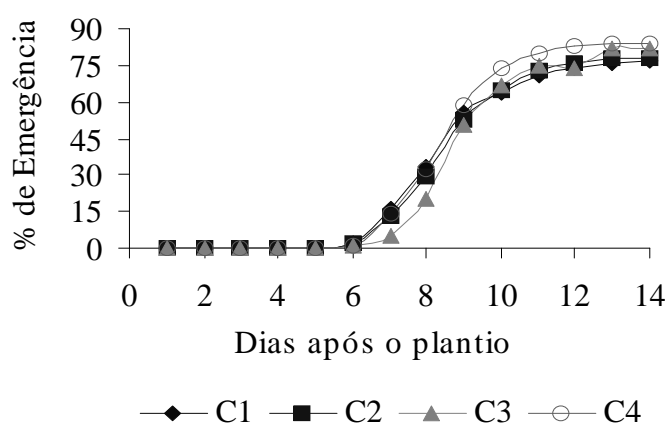

(b)

Figura 5 - Marcha de emergência das plântulas de soja, em função do teor de água do solo (a) e em função da carga aplicada pela roda compactadora sobre a semente (b).
29,2 e $15,3 \%$ das sementes que foram semeadas nos teores de água de 0,31 e $0,36 \mathrm{~kg} \mathrm{~kg}^{-1}$, respectivamente, atingiram a emergência.

Observa-se também, que a porcentagem de emergência da soja variou entre 69,2 e $85,6 \%$, para os teores de água U3 e U2 e entre 85,6 e 85,5\%, para os teores de água U2 e U1, respectivamente, (Figura 5a). Ao avaliar o efeito do fator carga aplicada na emergência (Figura 5b), verificou-se que esta ocorreu de forma semelhante para todas as cargas avaliadas e que a porcentagem de plântulas emergidas variou de 76,6 e 77,9\% para as cargas $\mathrm{C} 1$ e $\mathrm{C} 2$, e entre 77,9 e 81,6\%, para as cargas C2 e C3, e entre 81,6 e $83,8 \%$ para as cargas $\mathrm{C} 3$ e $\mathrm{C} 4$, respectivamente.

\section{CONCLUSÕES}

Concluiu-se, pelo presente trabalho, que a combinação entre teores de água e cargas aplicadas não influenciaram a resistência do solo à penetração, no plano vertical da linha de semeadura acima da profundidade de deposição da semente.

O maior índice de velocidade de emergência (IVE) ocorreu no teor de água igual de $0,33 \mathrm{~kg} \mathrm{~kg}^{-1}$ e na carga de $86,21 \mathrm{~N}$.

A carga máxima de $140 \mathrm{~N}$ aplicada pela roda compactadora sobre a semente, causou encrostamento superficial do solo, retardando assim a emergência das plântulas.

\section{AGRADECIMENTOS}

Ao $\mathrm{CNPq}$ pelo apoio financeiro para realização desse trabalho, a COODETEC pela área e estrutura física cedidas para a realização do experimento.

\section{REFERÊNCIAS BIBLIOGRÁFICAS}

CARDOSO, A. N. Manejo e conservação do solo na cultura da soja. In: SIMPÓSIO SOBRE A CULTURA DA SOJA NOS CERRADOS, 1992, Uberaba. Anais... Piracicaba: POTAFOS, 1993. p. 71-104.

EMPRESA BRASILEIRA DE PESQUISA AGROPECUÁRIA. Centro Nacional de Ciência do solo. Manual de métodos de análise de solos. 2. ed. Rio de Janeiro, 1997. $212 \mathrm{p}$.

FURLANI, C. E. A.; LOPES, A.; REZENDE, L. C.; SILVA, S. S. S. e; LEITE, M. A. S. Influência da compactação do solo na emergência das plântulas de milho a diferentes profundidades de semeadura. Engenharia na Agricultura, Viçosa, v. 9, n. 3, p. 147-153, 2001 
HAUSER, V. L. Water injection in grass seed furrows, Transactions of the ASAE, Saint Joseph, v. 29, n. 5, p. 1247-1253, 1986.

LANGE, A. Palhada e nitrogênio afetando propriedades do solo e rendimento de milho em sistema de plantio direto no cerrado. 2002. 148 f. Dissertação (Mestrado em Agronomia) - Universidade Federal de Lavras, Lavras, 2002.

MAGUIRE, J. D. Speed of germination-aid in selection and evaluation for seedling emergence and vigor. Crop science, Madison, v. 2, n. 1, p. 176-177, 1962.

MORAES, G. A. F.; MENEZES, N. L. Desempenho de sementes de soja sob condições diferentes de potencial osmótico. Ciência Rural, Santa Maria, v. 33, n. 2, p. 219 226, 2003.

NABI, G.; MULLINS, C. E.; MONTEMAYOR, M. B.; AKHTAR, M. S. Germination and emergence of irrigate cotton in Pakistan in relation to sowing depth and physical properties of the seedbed. Soil \& Tillage Research, Amsterdam, v. 59, n. 2, p. 33-44, 2000.

PRADO, R. M.; TORRES, J. L.; ROQUE, C. G.; COAN, O. Semente de milho sob compressão do solo e profundidade de semeadura: influência no índice de velocidade de emergência. Scientia Agrária, Curitiba, v. 2, n. 1, p. 45-49, 2001.
SILVA, F. M. Influência do tipo de rodas compactadoras de semeadoras-adubadoras, no condicionamento físico do solo e no desenvolvimento de plantas. 1990. 145 f. Dissertação (Mestrado em Engenharia Agrícola) - Universidade Estadual de Campinas, Campinas, 1990.

SILVA, F. M.; ORTOLANI, F. M.; DANIEL, L. A. Rodas compactadoras de semeadoras-adubadoras: influência no condicionamento físico do solo na região de semeadura. In: CONGRESSO BRASILEIRO DE ENGENHARIA AGRÍCOLA, 20., 1991, Londrina. Anais... Londrina: SBEA, 1991. p. 1126-1146.

SILVA, R. P. Efeito de rodas compactadoras submetidas a cargas verticais em profundidades de semeadura nas características agronômicas do milho (Zea Mays L.). 2002. 119 f. Tese (Doutorado em Agronomia) - Universidade Estadual Paulista, Jaboticabal, 2002.

TIEPPO, R. C. Desenvolvimento de um penetrômetro manual eletrônico. 2004. 43 f. Dissertação (Mestrado em Engenharia Agrícola) - Universidade Estadual do Oeste do Paraná, Cascavel, 2004.

TORMENA, C. A.; SILVA, A. P.; LIBARDI, P. L. Caracterização do intervalo hídrico ótimo de um Latossolo Roxo sob plantio direto. Revista Brasileira de Ciência do Solo, Campinas, v. 22, n. 4, p. 573-581, 1998. 